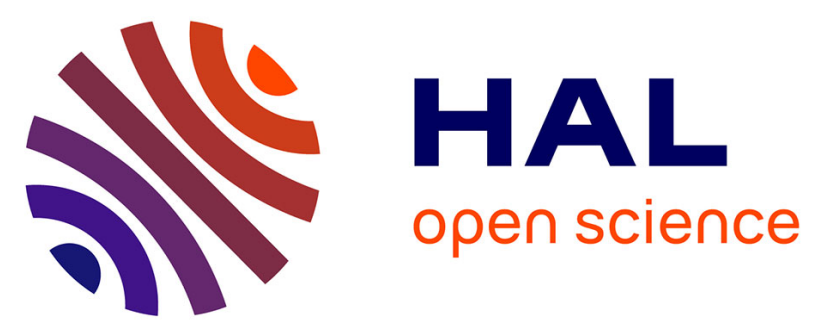

\title{
Characterization of relative abundance of lactic acid bacteria species in French organic sourdough by cultural, qPCR and MiSeq high-throughput sequencing methods
} Elisa Michel, Clarisse Monfort, Marion Deffrasnes, Stéphane Guezenec, Emilie Lhomme, Matthieu Barret, Delphine Sicard, Xavier Dousset, Bernard Onno

\section{To cite this version:}

Elisa Michel, Clarisse Monfort, Marion Deffrasnes, Stéphane Guezenec, Emilie Lhomme, et al.. Characterization of relative abundance of lactic acid bacteria species in French organic sourdough by cultural, qPCR and MiSeq high-throughput sequencing methods. International Journal of Food Microbiology, 2016, 239, pp.35-43. 10.1016/j.ijfoodmicro.2016.07.034 . hal-01527569

\author{
HAL Id: hal-01527569 \\ https://hal.science/hal-01527569
}

Submitted on 26 Sep 2017

HAL is a multi-disciplinary open access archive for the deposit and dissemination of scientific research documents, whether they are published or not. The documents may come from teaching and research institutions in France or abroad, or from public or private research centers.
L'archive ouverte pluridisciplinaire HAL, est destinée au dépôt et à la diffusion de documents scientifiques de niveau recherche, publiés ou non, émanant des établissements d'enseignement et de recherche français ou étrangers, des laboratoires publics ou privés. 


\section{Accepted Manuscript}

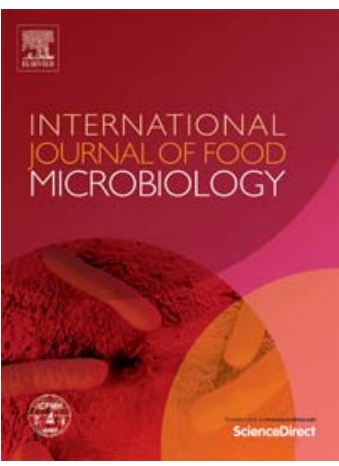

Eisa Michel, Clarisse Monfort, Marion Deffrasnes, Stéphane Guezenec, Emilie Lhomme, Matthieu Barret, Delphine Sicard, Xavier Dousset, Bernard Onno

Characterization of relative abundance of lactic acid bacteria species in french organic sourdough by cultural, qPCR and MiSeq high-throughput sequencing methods

PII: $\quad$ S0168-1605(16)30392-0

DOI: $\quad$ doi: $10.1016 / j . i j f o o d m i c r o .2016 .07 .034$

Reference: $\quad$ FOOD 7324

To appear in: $\quad$ International Journal of Food Microbiology

Received date: 4 February 2016

Revised date: $\quad 25$ July 2016

Accepted date: 27 July 2016

Please cite this article as: Michel, Elisa, Monfort, Clarisse, Deffrasnes, Marion, Guezenec, Stéphane, Lhomme, Emilie, Barret, Matthieu, Sicard, Delphine, Dousset, Xavier, Onno, Bernard, Characterization of relative abundance of lactic acid bacteria species in french organic sourdough by cultural, qPCR and MiSeq high-throughput sequencing methods, International Journal of Food Microbiology (2016), doi: 10.1016/j.ijfoodmicro.2016.07.034

This is a PDF file of an unedited manuscript that has been accepted for publication. As a service to our customers we are providing this early version of the manuscript. The manuscript will undergo copyediting, typesetting, and review of the resulting proof before it is published in its final form. Please note that during the production process errors may be discovered which could affect the content, and all legal disclaimers that apply to the journal pertain. 
Characterization of relative abundance of Lactic Acid Bacteria species in French organic sourdough by cultural, qPCR and MiSeq high-throughput sequencing methods

\title{
Authors
}

Elisa Michel a,b, Clarisse Monfort a, Marion Deffrasnes a , Stéphane Guezenec ${ }^{\text {b }}$, Emilie Lhomme a, Matthieu Barret ${ }^{\mathrm{c}}$, Delphine Sicard ${ }^{\mathrm{b}}$, Xavier Dousset ${ }^{\mathrm{d}}$, Bernard Onno ${ }^{\mathrm{a}}$

${ }^{a}$ Oniris, Laboratoire de Microbiologie Alimentaire et Industrielle, Rue de la Géraudière CS 82225, 44322 Nantes Cedex 3, France

${ }^{\mathrm{b}}$ INRA, UMR Sciences pour l'œnologie, 2 place Pierre Viala, 34060 Montpellier Cedex 01, France

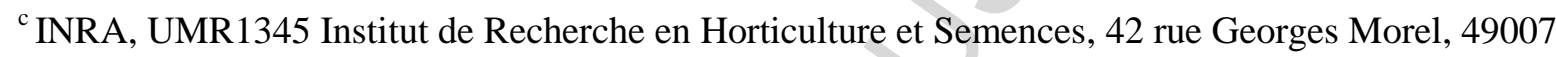
Beaucouzé Cedex, France

${ }^{\mathrm{d}}$ SECALIMUnit UMR1014,Oniris, INRA, Université BretagneLoire, Nantes, France.UMR INRA 1014 Secalim, La Chantrerie CS, 40307 Nantes Cedex 3, France

\section{Corresponding author: Bernard Onno, Xavier Dousset}

Oniris, Laboratoire de Microbiologie Alimentaire et Industrielle, CS 82225, 44322 Nantes Cedex 3

E-mail address: bernard.onno@oniris-nantes.fr, xavier.dousset@oniris-nantes.fr

\begin{abstract}
In order to contribute to the description of sourdough LAB composition, MiSeq sequencing and qPCR methods were performed in association with cultural methods. A panel of 16 French organic bakers and farmer-bakers were selected for this work. The lactic acid bacteria (LAB) diversity of their organic sourdoughs was investigated quantitatively and qualitatively combining (i) Lactobacillus. sanfranciscensis-specific qPCR, (ii) global sequencing with MiSeq Illumina technology and (iii) molecular isolates identification. In addition, $\mathrm{LAB}$ and yeast enumeration, $\mathrm{pH}$, Total Titratable Acidity, organic acids and bread specific volume were analyzed. Microbial and physico-chemical data were statistically treated by Principal Component Analysis (PCA) and Hierarchical Ascendant Classification (HAC). Total yeast counts were $6 \log _{10}$ to $7.6 \log _{10} \mathrm{CFU} / \mathrm{g}$ while LAB counts varied from $7.2 \log _{10}$ to $9.6 \log _{10} \mathrm{CFU} / \mathrm{g}$. Values obtained by L. sanfranciscensis-specific qPCR were estimated between 7.2 and $10.3 \log _{10} \mathrm{CFU} / \mathrm{g}$, except for one sample at $4.4 \log _{10} \mathrm{CFU} / \mathrm{g}$. HAC and PCA clustered the sixteen sourdoughs into three classes described by their variables but without links to bakers' practices. L. sanfranciscensis was the dominant species in 13 of the 16 sourdoughs analyzed by Next Generation Sequencing (NGS), by the culture dependent method this species was dominant only in only 10 samples. Based on isolates identification, LAB diversity was higher for 7 sourdoughs with the recovery of L. curvatus, L. brevis, L. heilongjiangensis, L.xiangfangensis, L. koreensis, $L$.
\end{abstract}


pontis, Weissella sp. and Pediococcus pentosaceus, as the most representative species. L. koreensis, L. heilongjiangensis and L. xiangfangensis were identified in traditional Asian food and here for the first time as dominant in organic sourdough. This study highlighted that $L$. sanfranciscensis was not the major species in 6/16 sourdough samples and that a relatively high LAB diversity can be observed in French organic sourdough.

Keywords: organic sourdough, Lactic Acid Bacteria, molecular characterization, qPCR, MiSeq

\section{Introduction}

Bread is a staple in many European countries and the production of sourdough breads is part of a cultural and geographical identity (De Vuyst and Neysens, 2005). Despite a number of technical constraints, natural sourdough has advantages such as enhancing bread flavor, prolonging the shelf life, improving the dough structure as well as increasing the nutritional value (Minervini et al., 2014). The microbiota of a stable sourdough principally consists of lactic acid bacteria (LAB) and yeasts (Huys et al., 2013). New species of the genus Lactobacillus have been isolated from traditional sourdoughs and various studies on sourdough from different countries have been conducted to isolate a wide range of LAB (De Vuyst and Vancanneyt, 2007). Although they mostly belong to the genus Lactobacillus, other genera such as Leuconostoc, Weissella, Pediococcus and Enterococcus have also been identified (Gobbetti and Gänzle, 2012). Many species have been found, such as L.sakei, L. crustorum, L. nantensis, L. mindensis, L. reuteri, L. brevis, L. plantarum, L. buchneri, L. curvatus, L. panis, L. pontis, L. sanfranciscensis, L. spicheri, L. kimchi, L. amylovorus, L. casei, W. cibaria, and W. confusa (De Vuyst et al., 2014; Gobbetti and Gänzle, 2012). For yeasts, the six most common yeast species found in stable sourdoughs are S. cerevisiae, Kazachstania exigua, Candida humilis, Pichia kudriavzevii, Torulaspora delbrueckii, and Wickerhamomyces anomalus (De Vuyst et al., 2014). Regarding French ones, L. plantarum and Pediococcus pentosaceus were found to be dominant (Robert et al., 2009). Other studies revealed a higher diversity with species such as L.hammesii and L.nantensis (Valcheva et al., 2006, 2005). For French organic and conventional sourdoughs, recent studies demonstrated that their microbiota contain mainly L. sanfranciscensis (Lhomme et al., 2015a, 2015b) and Kazachstania bulderi and K. unispora as dominant yeast species (Lhomme et al., 2016). Recently, the rise in culture-independent methods has provided additional data to culture-dependent techniques. Several culture-independent techniques such as pyrosequencing (Bessmeltseva et al., 2014; Ercolini et al., 2013; Lattanzi et al., 2013; Lhomme et al., 2015b), MiSeq ((Minervini et al., 2015), HRM-qPCR (quantitative High Resolution Melting PCR) (Lin and Gänzle, 2014), and quantitative PCR (Lee et al., 2015; Scheirlinck et al., 2009) have been used to study sourdough microbial diversity. The aim of this paper was to analyze quantitatively and qualitatively the LAB relative abundance of organic sourdoughs. A panel of 16 bakers using natural sourdough and organic 
flours were selected for this study. They were characterized by their practices (farmer-bakers, artisanbakers and industrial-bakers) and their geographical location. To describe LAB diversity, we combined (i) sourdough isolate identification, (ii) L. sanfranciscensis quantitative PCR and (iii) global sequencing with MiSeq Illumina technology.

\section{Materials and Methods}

\subsection{Sourdough and bread sampling}

Sixteen bakers located in different regions of France were selected (Table 1). They were also chosen because of their bakers' status and related practices: farmer-bakers who produce their own flour (B15, B20, B21, B22, B25 and B27), artisan bakers (B16, B17, B18, B19 and B24) or industrial bakers (B23, B26, B28, B29 and B30). Sourdoughs were collected at the end of the last backslopping as mature sourdoughs (final leavened dough) and final breads were also sampled. Both were stored in sterile vials and conserved at $4{ }^{\circ} \mathrm{C}$ until analyses.

\subsection{Microbial analysis}

For each sample, sourdough was ten-fold diluted in TS $(0.1 \%$ tryptone, $0.85 \% \mathrm{NaCl})$ and mixed for 2 min with a Stomacher (AES Laboratoire, France). Cascade dilutions were performed from $10^{-2}$ to $10^{-6}$ and then plated with a spiral plater (Interscience, Saint-Nom-la-Bretèche, France) on MRS5 characterized by a vitamin mix addition (Meroth et al., 2003; Vera et al., 2009) for LAB enumeration and YPD (4 g/L Yeast Extract, $8 \mathrm{~g} / \mathrm{L}$ glucose, $6.8 \mathrm{~g} / \mathrm{L}$ agar) for yeast enumeration. Plates were incubated for $48 \mathrm{~h}$ at $30^{\circ} \mathrm{C}$ under anaerobic conditions (Anaerocult A, Merck, Darmstadt, Germany) for $\mathrm{LAB}$ and at $26{ }^{\circ} \mathrm{C}$ under aerobic conditions for yeast. After LAB enumeration, approximately 15 bacterial colonies from each sample were selected and, after overnight culture on MRS, maltose $(0.05 \%)$ and cysteine $(1 \%)$, these were stored at $-80{ }^{\circ} \mathrm{C}$ with $40 \%$ glycerol. LAB isolates were identified by partial or whole 16S rDNA sequencing. The 16S rDNA (about $1500 \mathrm{bp}$ ) of the pure LAB isolates was amplified by PCR as described previously (Jaffrès et al., 2009) from chromosomal DNA using primers fD1 and rD1 (Weisburg et al., 1991). The sequencing primers SP1, SP2, SP3, and SP5 targeting two conserved regions of the 16S rRNA gene were used (Lhomme et al., 2015a). The partial nucleotide sequence (about $700 \mathrm{bp}$ ) of the amplified 16S rDNA gene was determined using the sequencing primer SP1. To confirm species group identity, the whole 16S rDNA gene was sequenced (about $1500 \mathrm{bp)}$ ) using sequencing primers SP. Forward and reverse sequences obtained with SP1 and SP2 or with SP3 and SP5 (Table 2) were concatenated with BioEdit. A similarity of at least $97.6 \%$ to 16S rDNA gene sequences of type strains was used as the criterion for identification (Stackebrandt and Ebers, 2006). As the 16S rDNA sequence did not discriminate Lactobacillus plantarum, Lactobacillus paraplantarum and Lactobacillus pentosus, a multiplex PCR targeting the recA gene (Torriani et al., 2001) was performed. Three forward primers (para-F, pent-F and F-Plan) specific for 
each species and a common reverse primer (pREV) were used (Table 2), expecting an amplicon size depending on the species: 107, 218 and 318 bp for L. paraplantarum, L. pentosus and L. plantarum, respectively. In addition, a PCR targeting the katA gene (407 bp) was used (Ammor et al., 2005) to discriminate 16S rDNA identification of Lactobacillus sakei and Lactobacillus curvatus (Table 2). Similarly, as the 16S rDNA sequence did not discriminate all lactic acid bacteria, rpoA and pheS genes sequencing was performed for $L$. koreensis and L.heilongjiangensis identification, using the sequencing primers (Table 2) rpoA-21-F/rpoA-23-R and pheS-21-F and pheS-23-R (Naser et al., 2007). Identification queries were fulfilled by a BLAST search against the National Center for Biotechnology Information (NCBI, Bethesda, USA), the BIBI (Devulder et al., 2003) and the Ribosomal Data Project (Cole et al., 2011) databases.

Single colonies from pure bacterial cultures grown on MRS plates were transferred onto Biolog universal growth $\left(\mathrm{BUG}^{\mathrm{TM}}\right.$ ) agar (Biolog Inc., Hayward,CA) and incubated at $28^{\circ} \mathrm{C}$ for $24 \mathrm{~h}$. Colonies were picked using a sterile moistened Biolog cotton swab, suspended in sterile inoculating fluid, IF-A (Biolog Inc., Hayward, CA) and concentration adjusted to match Biolog GEN III turbidity standards. Aliquots of $100 \mu \mathrm{L}$ of bacterial suspensions were loaded into each well of the Microplates. Each bacterial isolate was inoculated on a separate Biolog GEN III MicroPlates ${ }^{\mathrm{TM}}$. Readings of inoculated Biolog GEN III microplates was performed at 580nm (Tecan Infinite Pro 200, Salzburg, Austria) after 24-48 h of incubation at $30^{\circ} \mathrm{C}$. All the wells start out colorless when inoculated. During incubation, there was increased respiration in the wells where cells could use a carbon source and/or grow. Increased respiration causes reduction of the tetrazolium redox dye, forming a purple color. Negative wells remain colorless as did the negative control well with no carbon source. A positive control well was also used as reference for the chemical sensitivity assays.

2.3. Determination of TTA (Total Titratable Acidity), $\mathrm{pH}$, bread mass density and organic acids

Sourdough samples were ten-fold diluted with distilled water and mixed with a Stomacher for 2 min (AES Laboratoire, France). Each sample was analyzed in triplicate with an automatic titrator (pHMatic 23, Grosseron, Saint-Herblain, France), using a 10-mL volume and N/10 NaOH solution concentration. The results of the TTA assay were expressed in volume of $0.1 \mathrm{M}$ sodium hydroxide used to neutralize a $10 \mathrm{~g}$ sample (Romanian Standard Methods 90/2007). To measure the bread specific volume, rapeseed density was used. The bread was added in the same container and the excess seed mass was calculated, expressed in $\mathrm{dm}^{3} / \mathrm{kg}$. To measure organic acids, $6 \mathrm{ml}$ of the homogenized mixture was centrifuged at 13,000 rpm for $5 \mathrm{~min}$ at room temperature. The samples were clarified by Carrez reagents I and II $(250 \mu \mathrm{L})$ and centrifuged at 13,000 rpm for $5 \mathrm{~min}$. The supernatant (watersoluble extract) was then analyzed for its organic acid concentration; it was diluted with $10 \mathrm{mM}$ $\mathrm{H}_{2} \mathrm{SO}_{4}$ and analyzed by liquid chromatography using an HPLC system (Zeppa et al., 2001). Acid amounts were expressed as $\mathrm{g} / \mathrm{kg}$ of sourdough, dough or bread. 


\subsection{Statistical analysis}

$\mathrm{LAB}$ and yeast microbial counts, L. sanfranciscensis concentration estimation and biochemical characteristics were used as variables for statistical analyses. Principal Component Analysis (PCA) was carried out to describe the relations between sourdough, bread physico-chemical and microbiological variables. Hierarchical Ascendant Classification (HAC) was carried out to cluster sourdoughs and build a partition into homogeneous clusters. These tests were performed using XLstat (Addinsoft, 2007) and Rstudio Version 3.2.5 http://www.rstudio.com/ (Team, 2015).

\subsection{Sourdough DNA extraction}

Sourdough samples were five-fold diluted in TS $(0.1 \%$ tryptone, $0.85 \% \mathrm{NaCl})$, then Tween 80 was added and mixed for $2 \mathrm{~min}$ in a stomacher (AES Laboratoire, France). The matrix was transferred to a NucleoSpin ${ }^{\circledR}$ tube. After centrifugation at $8500 \mathrm{rpm}$ for $10 \mathrm{~min}$, the bacterial pellet was taken up in a lysis solution (1 M Tris-HCl, pH 8, 0.1 M Na-EDTA, Triton X100, 100 mg lysozyme/ml, mutanolysin $200 \mathrm{U} / \mathrm{ml}$ ). The solution was then incubated at $37^{\circ} \mathrm{C}$ and a vibratory lysis step using glass beads was performed (mini BeadBeater- $8 \AA$, Biospec, California, USA). The samples were placed in an ice tray to burst the cells by thermal shock. After addition of $25 \mu \mathrm{L}$ of proteinase $\mathrm{K}$ and $200 \mu \mathrm{L}$ of AL buffer, the samples were incubated at $56^{\circ} \mathrm{C}$ for $1 \mathrm{~h}$ then centrifuged for $3 \mathrm{~min}$ at $10000 \mathrm{rpm}$. Two hundred $\mu \mathrm{L}$ of ethanol was added and the mix was transferred to a Qiagen column. Two successive steps of washing with $500 \mu \mathrm{L}$ of Buffer AW1 and Buffer AW2 were carried out. After each centrifugation (8000 rpm for $1 \mathrm{~min}$ ), the filtrates were discarded. DNA was eluted in $100 \mu \mathrm{L}$ of elution solution by centrifugation at $8000 \mathrm{rpm}$ for $1 \mathrm{~min}$. DNA was stored at $-20^{\circ} \mathrm{C}$ and its concentration and purity were checked using a spectrophotometer (Nanodrop ND-100; Nanodrop Technologies).

\subsection{Quantitative PCR to detect $L$. sanfranciscensis}

The pheS gene was amplified from sourdough DNA with primers LS-1F and LS-1R, as described by Scheirlinck et al. (2009). Previously, a standard curve was constructed on a target strain $L$. sanfranciscensis ATCC 43332, in the range 4-10 log CFU/g (Lhomme et al., 2015b). In addition, one non-inoculated dough was used as the negative control. The different bacterial cell densities were plotted against the corresponding CT values (Opticon Monitor Software $3 \circledR$ ). Amplification efficiency (E) was calculated as $\mathrm{E}=10^{-1} /$ slope (Klein, 2002). L. sanfranciscensis in the sourdough samples was quantified by qPCR, using the mean values of CT obtained in three independent qPCR experiments.

\subsection{Sequencing on MiSeq Illumina}

After sourdough DNA extraction, amplicon libraries were constructed following two rounds of PCR amplification. The first step was performed with the PCR primers $515 \mathrm{f}$ and 806r (Caporaso et al., 2011) which target the V4 region of the 16S rRNA gene. Forward and reverse primers carried the 
GGAGTTCAGACGTGTGCTCTTCCGATCT-3' tails, respectively. All PCR reactions were performed with a high-fidelity polymerase (AccuPrime Taq DNA Polymerase System; Invitrogen) using the manufacturer's protocol and $\mathrm{x} \mu \mathrm{l}$ of environmental DNA (approximately $\mathrm{x} n \mathrm{ng}$ ). Cycling conditions for 515f/806r were adapted from Caporaso et al. (2011). Briefly, reactions were held at 94 ${ }^{\circ} \mathrm{C}$ for $2 \mathrm{~min}$, followed by 30 cycles of amplification at $94{ }^{\circ} \mathrm{C}(30 \mathrm{~s}), 50{ }^{\circ} \mathrm{C}(60 \mathrm{~s})$ and $68{ }^{\circ} \mathrm{C}(90 \mathrm{~s})$ with a final extension step of $10 \mathrm{~min}$ at $68{ }^{\circ} \mathrm{C}$. All amplicons were purified with the Agencourt AMPure XP system and quantified with QuantIT PicoGreen. A second round of amplification was performed with $5 \mu \mathrm{l}$ of purified amplicons and primers containing the Illumina adapters and indexes. PCR cycling conditions were: $94{ }^{\circ} \mathrm{C}(2 \mathrm{~min})$, followed by 12 cycles of amplification $\left(94{ }^{\circ} \mathrm{C}\right.$ for $1 \mathrm{~min}$, $55{ }^{\circ} \mathrm{C}$ for $1 \mathrm{~min}, 68{ }^{\circ} \mathrm{C}$ for $\left.1 \mathrm{~min}\right)$ and a final extension step at $68{ }^{\circ} \mathrm{C}(10 \mathrm{~min})$. All amplicons were purified and quantified as previously described. The purified amplicons were then pooled in equimolar concentrations and the final concentration of the library was determined using a Kapa qPCR Quantification Kit. Amplicon libraries were mixed with 5\% PhiX control according to the Illumina protocols. The sequencing run was performed with MiSeq Reagent Kit v3 (600 cycles) (Barret et al., 2015).

\subsection{Sequence analyses}

Raw reads were analyzed using the steps described in the standard operating procedure of Mothur at http://www.mothur.org/wiki/MiSeq_SOP (Kozich et al., 2013). Briefly, 16S rRNA gene sequences were aligned against the 16S rRNA gene SILVA alignment using Mothur v1.33 (Schloss et al., 2009). Chimeric sequences were detected with UCHIME (Edgar et al., 2011) and subsequently removed from the dataset. Taxonomic affiliation of 16S rRNA genes was performed with a Bayesian classifier (Wang et al., 2007) (80\% bootstrap confidence score) against the 16S rRNA gene training set (v9) of the Ribosomal Database Project (Cole et al., 2011). Unclassified sequences or sequences belonging to Eukaryota, Archaea, chloroplasts or mitochondria were discarded. Sequences were assigned to operational taxonomic units (OTUs) at $97 \%$ identity. Only abundant OTUs representing at least $0.1 \%$ of the library size were conserved for microbial community analyses (Barret et al., 2015). Taxonomic affiliation of these OTUs was done using BLAST+ and RDP against the different databases: NCBI, BIBI and RDP (Cole et al., 2011; Devulder et al., 2003; The NCBI Handbook, 2013).

\section{Results and discussion}

\subsection{Enumeration of total $\mathrm{LAB}$ and yeast microflora}

The number of total LAB enumerated on MRS5 medium ranged from $7.19 \log _{10}$ to $9.62 \log _{10} \mathrm{CFU}$ with a mean value of 8.92 (Table 3). Sourdough B29 presented a low concentration, $7.19 \log _{10} \mathrm{CFU} / \mathrm{g}$ of $\mathrm{LAB}$, in comparison with other sourdoughs. The yeast population ranged from $5.92 \log _{10}$ to 7.68 
$\log _{10} \mathrm{CFU} / \mathrm{g}$, with a mean value of 7.19 . The yeast/LAB ratio ranged from $0.15 \%$ to $66.07 \%$. The vast majority of sourdoughs present a low ratio < 10\%, except for B22 and B29 (38.9\% and 66.07\% respectively). These results are consistent with those previously found for French and European sourdoughs (Gobbetti et al., 1994; Lhomme et al., 2015b).

\subsection{Physical and chemical characteristics}

TTA acidity, $\mathrm{pH}$ and bread specific volume are presented in Table 3. The $\mathrm{pH}$ of the sourdoughs ranged from 3.62 to 4.03 , the breads from 3.98 to 4.96. Similarly, the TTA varied from 13.3 to 21.3 and 6.9 to $10.5 \mathrm{~mL} \mathrm{NaOH} 0.1 \mathrm{~N}$ for sourdoughs and bread, respectively. These are expected values. Dough acidity is mostly due to the metabolic activity of LAB (Gänzle and Gobbetti, 2015). This lower bread acidity is related to the dilution of the sourdough during its incorporation into the dough. The short fermentation time of the final dough (approximately 4 hours) prevents sufficient production of organic acids and a part is lost by volatilization during baking. TTA values vary depending on the nature of flours (Banu et al., 2011; Katina et al., 2005) and the fermentation temperature: at higher temperature, LAB produce organic acids more efficiently (Minervini et al., 2014). The bread specific volume varied between 1.81 and $2.80 \mathrm{dm}^{3} / \mathrm{kg}$. These variations are due to the amount and activity of yeasts present in the sourdough and gas production. However, the dough retention capacity and the final volume are also related to flour properties, proteolytic activity (Thiele et al., 2002) and baking practices. Lactic acid values varied from 3.37 to $11.96 \mathrm{~g} / \mathrm{kg}$ and acetic acid values from 0.91 to $4.44 \mathrm{~g} / \mathrm{kg}$. The fermentative quotient varied from 1.06 to 5.66; these are expected values consistent with previous observations (Lhomme et al., 2015a; Valmorri et al., 2010). The sourdough and bread samples studied here come from different bakers using different flours, with different baking practices in terms of temperature and the proportion of sourdough used in the final dough. These variable conditions explain the physico-chemical differences observed.

\subsection{Estimated number of $L$. sanfranciscensis in sourdough by quantitative PCR}

Because of the predominance of $L$. sanfranciscensis in French organic sourdough (Lhomme et al., 2015b), the qPCR technique was used to assess the L. sanfranciscensis population in sourdoughs (Gobbetti and Corsetti, 1997; Lee et al., 2015). Scheirlinck et al. (2009) showed the value of this method to estimate quickly the presence and amount of this species in a sample. Here, $L$. sanfranciscensis qPCR estimates varied from 4.41 to $10.29 \log _{10}$ CFU/g (Table 4). For 13/16 sourdoughs (all but B23, B25, B28), the number of L. sanfranciscensis estimated by qPCR represented more than $90 \%$ (qPCR / total LAB ratio > 0.9) of the total number of LAB (Table 4), showing that $L$. sanfranciscensis was the main LAB species in these sourdoughs. These results are consistent with those found by Lhomme et al. (2015b), in which L. sanfranciscensis was predominant in 10/15 sourdoughs analyzed. 
The observed overestimation (ratio $>1$ ) of $L$. sanfranciscensis by qPCR compared to the total number of LAB for 7/16 samples (Tables 3 and 4), may be related to an underestimation of the LAB enumeration due to the selectivity of the medium MRS5. However, this medium is the most suitable to enable isolation of specific LAB species in bread sourdough (Vera et al., 2009). Alternatively, the qPCR method can enumerate viable and non-cultivable $L$. sanfranciscensis cells, i.e. living and dead bacteria. In order to differentiate living and dead cells specific PCR and sample treatment with PMA (propidium monoazide) may be combined to determine the viable population quantitatively (Macé et al.; 2013). For Hierro et al. (2006), RT-qPCR could be an alternative method to rule out the counting of dead cells.

\subsection{Sourdough isolate identification}

To complete and investigate LAB diversity, isolates were identified using $16 \mathrm{~S}$ rDNA and rpoA sequence analysis. The results are shown in Table 4. For 7 sourdoughs (B17, B18, B19, B20, B22, B24 and B27) 100\% of isolates belonged to L. sanfranciscensis species. For 3 sourdoughs (B26, B21 and B1), L. sanfranciscensis represented more than $50 \%$ of isolates. For 6 sourdoughs of the 16 studied, L. sanfranciscensis was not dominant or absent (B16, B23, B25, B28, B29 and B30).

Sourdough B16 isolates belonged to L. curvatus (90\%) and L. plantarum (10\%) species. For sourdough B25, isolates were identified as L. brevis (69\%), L. plantarum (15\%), L. sanfranciscensis $(8 \%)$ and $L$. paralimentarius (8\%). Sourdough B28 isolates were classified as $L$. sanfranciscensis (40\%), L. pontis (33\%), L. diolivorans (13\%), L. paracasei (7\%), and L. parabuchneri (7\%). Greater genera diversity was observed in the sourdough B30 with P. pentosaceus and Weissella confusa as the dominant species. In sourdough B29, L. xiangfangensis was isolated for the first time in sourdough as the prevailing $\mathrm{LAB}$ species.

Finally, sourdough B23 was unique here because of its low value of L. sanfranciscensis (4.41 $\log _{10}$ CFU/g) estimated by qPCR compared to a total of $9.02 \log _{10} \mathrm{LAB}$. Isolates were sorted into 4 distinct groups according to their rDNA $16 \mathrm{~S}$ sequence homology. The first group was identified as $L$. curvatus by rDNA $16 \mathrm{~S}$ and katA gene absence by PCR amplification (Ammor et al., 2005). For the second group, three species were identified on the basis of 16S sequencing (L. plantarum, L. pentosus, L. paraplantarum). Using recA amplicon size variation (Torriani et al., 2001), the isolates were identified as being L. plantarum (amplicon size of $318 \mathrm{bp}$ ). Isolates from group 3 were identified by rDNA 16S sequencing as belonging to L. heilongjiangensis (100\%). Using rpoA and pheS genes (Gu et al., 2013; Naser et al., 2007), L. heilongjiangensis identity was confirmed with 99\% and 96\% homology respectively and distinguished from closely-related LAB species as L. nantensis, $L$. mindensis, L. crustorum or L. farciminis. Finally, for group 4, rDNA 16S sequences showed 97\% of homology with L. koreensis and $95 \%$ of homology with L. parabrevis using RDP database. With BIBI database, the closest sequence based on patristic distances was Lactobacillus koreensis T FJ904277 
with $100 \%$ of identity. Adding sequencing of $r p o A$ gene and pheS gene, the presence of L. koreensis in sourdough B23 was confirmed.

For 7 sourdough samples (B16, B21, B23, B25, B28, B29 and B30), LAB diversity was higher than previously found in French organic sourdoughs (Lhomme et al., 2015a).

The sourdough LAB diversity observed here was characterized by new species isolated in sourdough: L. xiangfangensis, L. heilongjiangensis and L. koreensis. Regarding L. xiangfangensis, it has been isolated in Chinese pickles (Gu et al., 2012). Already identified in French sourdough (Lhomme et al., 2015a), its occurrence was confirmed here in two sourdoughs (B21 and B29). It belongs to the L.plantarum species group and produces acid from diverse carbohydrate substrates such as ribose, D xylose, glucose, sucrose, fructose, and maltose. Its genome has been sequenced (Sun et al., 2015). L. heilongjiangensis had previously been found in traditional Chinese pickles (Gu et al., 2013) and was isolated here for the first time in sourdough (B23). It is a Gram-positive, catalase-negative, non-sporeforming rod and produces acid from many carbon substrates. The metabolic profile of $L$. heilongjiangensis strain revealed the use of mainly glucose, fructose, mannose and sucrose (Table S1). The complete genome is $2.79 \mathrm{Mbp}$, devoid of plasmids, and with a GC content of $37.5 \%$. Pathways involved in the biosynthesis of riboflavin and folate were identified in the genome of $L$. heilongjiangensis DSM 28069T, which are present in some other probiotic LAB strains (Zheng et al., 2015). Considering L. koreensis, previously isolated from Kimchi (Bui et al., 2011), it was also isolated in sourdough (B23) for the first time. Closely related to L. brevis, L. koreensis is an heterofermentative species and metabolizes mainly fructose, glucose, and maltose (Table S2). Its genome has been sequenced recently (Sun et al., 2015). The genomic diversity of L. xianfangensis, $L$. heilongjiangensis and L. koreensis could be described by analyzing and comparing genome sequences. Their genomes were sequenced with 210 other Lactobacillus strains by Sun et al., (2015): they presented a robust phylogenomic framework of existing species and for classifying new species.

\subsection{Relative abundance of LAB species estimated by Illumina MiSeq Sequencing}

To complement the cultural and molecular approaches, the relative abundance of species in the 16 samples was determined by NGS with Illumina MiSeq technology. A total of 777,750 quality-trimmed sequences of 16S RNA gene amplicons were obtained. The average number of sequences per sample was 51,850. After analysis, a total of 20 OTUs were identified, with a range of 1 to 8 OTUs per sourdough. Table 4 shows the OTUs found with a relative abundance of at least $0.1 \%$ for each sourdough. For 12 sourdoughs, B15, B17, B18, B19, B20, B21, B22, B24, B26, B27, B29, and B30, L. sanfranciscensis was present at more than $98 \%$. This OTU was also detected at much lower abundance in B25 and B28 sourdough samples (36.1\% and 88.8\%, respectively) and at very low abundance in B23 and B16 samples ( $0.2 \%$ and $0.1 \%$, respectively). With a relative abundance of $75.2 \%$, L. curvatus 
was the predominant species in B16 sourdough. For sourdough B25, the predominant species (61.9\%) corresponded to an OTU that was identified only at the taxonomic genus level, Lactobacillus sp. Similarly, other OTUs in sourdough B15 (0.1\%), B16 (12.0\%), B21 (0.1\%), B26 (0.6\%) and B30 $(0.1 \%)$ were affiliated only to the genus Lactobacillus. Finally, the OTU corresponding to $80.07 \%$ in B23 sourdough could not be formally related to a species, but was either L. koreensis or L. brevis. In sourdoughs B21, B29 and B30, the same OTU was detected with a relative abundance of $0.1 \%, 0.2 \%$ and $0.1 \%$, respectively. In B23 sourdough, the OTU corresponding to $16.7 \%$ could not be related to a species, but was either L. heilongjiangensis, L. farciminis or L. crustorum. Other sub-dominant species detected in the sourdoughs (relative abundance of 0.1\%-4.3\%) were Weissella found in B16 (0.2\%) and B30 (0.4\%), Pediococcus pentosaceus in B30 (0.2\%), L. sakei in B16 (0.7\%), L. brevis in B25 (0.9\%), L. nantensis in B23 (0.8\%), Leuconostoc in B23 (0.4\%), and L. parabrevis in B25 (0.6\%) and B28 (2.4\%). L. pontis was detected at a relative abundance of $4.3 \%, L$. buchneri at $0.8 \%$ and $L$. diolivorans at $2.3 \%$, in B28 sourdough. These Miseq analysis observations could reveal a relatively higher biodiversity considering subdominant LAB species.

\subsection{Comparison of LAB diversity analyzed by the different approaches}

Quantitative PCR showed that L. sanfranciscensis was the dominant species in 13 of the 16 sourdoughs studied. For 12 of the 13 samples, L. sanfranciscensis was also present at a high relative abundance estimated by MiSeq analysis (98.6\%), consistent with the qPCR quantification (Table 4). Moreover, a significant correlation was observed between these two methods $\left(R^{2}=0.68\right.$, data not shown) in PCA analysis (Figure 1C). For 10 sourdoughs, culture-dependent method confirmed L.sanfranciscensis dominance $(>50 \%)$ and were in agreement with culture-independent methods. Likewise, in sourdough B16, L. curvatus was predominant by the molecular method and MiSeq analysis confirming the possible occurrence of this species in sourdough as already described (Lhomme et al., 2015b; Robert et al., 2009). For sample B28, MiSeq results were partly consistent with the molecular characterization of isolates including $L$. sanfranciscensis dominance. Thus $L$. pontis, L. diolivorans and L. buchneri related sp. were also identified by these two methods.

Regarding sourdough B25, the results were not totally consistent between MiSeq and the cultural method. While L. sanfranciscensis and L. brevis were found by both methods, this was not the case for L. plantarum and L.paralimentarius, only identified as isolates. However, these species might have been classified as Lactobacillus species and could not be characterized more precisely by the MiSeq method. The same analysis and comments can be made for B26 and B30. Surprisingly, sourdough B29 analysis revealed a discrepancy regarding MiSeq results and isolate identification. Bias in the DNA extraction, sequence analyses or in sequencing might have occurred. Furthermore, the databases used could be incomplete or may contain poor quality sequences (Ercolini, 2013). Medium composition and strain- specific requirements could also contribute to this divergence. 
Finally, the most original sourdough of our study was sample B23. L. sanfranciscensis was found with a relative abundance of $0.17 \%$ in MiSeq analyses, corresponding to the low population $(\log 4.41$ CFU/g) estimated by qPCR. By molecular analysis of isolates, 37.5\% of L. heilongjiangensis was found, $25 \%$ of L. plantarum, $25 \%$ of L. koreensis and $12.5 \%$ of L. curvatus. This species might also have been detected by MiSeq analysis. However, the MiSeq method could not discriminate between three closely-related species, due to a too short sequence used. MiSeq analysis could be extended to obtain more detailed and specific results by searching for primers amplifying a longer and more discriminating $16 \mathrm{~S}$ rDNA sequence, or using housekeepings genes as gyrB or $r p o A$.

The results obtained here by the three methods partially confirm previous studies for traditional Italian sweet leavened baked goods (Lattanzi et al., 2013) and French organic sourdoughs (Lhomme et al., 2015b). One major point of this work is that LAB species diversity was higher than previously described (Lhomme et al. 2015a) for French organic sourdough. Our results are in agreement with the observations of Rizzello et al. (2015), showing that Firmicutes diversity was the highest for sourdough made with organic durum flours.

3.7. Relationships between bread and sourdough physico-chemical and microbiological characteristics by Hierarchical Ascendant Classification

Hierarchical Ascendant Classification (HAC) was carried out to cluster sourdoughs according to microbial counts, L. sanfranciscensis amount estimation (qPCR and MiSeq) and physico-chemical characteristics (Table 3 and 4). Three clusters were differentiated (Figure 1B). Cluster 1 grouped 6 sourdoughs, B15, B22, B24, B26, B27 and B28. Compared to the other clusters, this cluster was characterized by the lowest NLAB values counts and surprisingly the highest sourdough/bread acidity characteristics TTA, pH, acetic acid (Table 3). Four sourdoughs were associated in cluster 2, B16, B19, B23 and B25. They were characterized by the highest N LAB concentration counts, associated with low values for L. sanfranciscensis estimation (qPCR, Miseq Relative Abundance). For this cluster low acidity values were observed (sourdough /bread pH and TTA, lactic acid concentration). Enumeration media selectivity and intraspecific LAB diversity could explain these results (Foschino et al., 2001; Venturi et al., 2012). Finally cluster 3 grouped the remaining sourdoughs B17, B18, B20, B21, B29 and B30. They were characterized by yeast counts, high L. sanfranciscensis estimation (qPCR, Miseq Relative Abundance), low acetic acid concentration and high Fermentative Quotient. Furthermore, in this cluster the low number of yeasts could be related to the low bread volume. Regarding acetic acid concentration, the low number of yeasts for cluster 3 could have an impact on fructose production through sucrose metabolism (Gobetti et al., 1994; Meignen et al., 2001; Stolz et al., 1995). Overall, it is quite difficult to evaluate the relative contribution of LAB and yeasts for a given sample in terms of lactic and acetic acids balance. 
HAC clustering (Table 5, Figure 1B) was completed by PCA analysis (Figure 1C). Miseq and qPCR L. sanfranciscensis estimation are statistically linked and also correlated with sourdough TTA. These results might be explained by the acidification capacity of $L$. sanfranciscensis in sourdough (Gobbetti and Corsetti, 1997). Surprisingly, acetic acid concentration was not related to microbiological counts and L. sanfranciscensis estimation. Yeast LAB interactions might explain these unexpected results. Furthermore, bakers' practices or status as defined in this study - farmer-bakers, industrial-bakers and artisan-bakers - were not significantly different on the physicochemical or microbiological responses considered here (Figure 1D). LAB diversity observed here, could partially explain these results. However, backslopping frequency might influence microbiota and sourdough characteristics (Huys et al., 2013). Moreover, Minervini et al. (2014) had observed relationships between bread physicochemical characteristics and sourdough microbiological data and baking practices during the traditional sourdough process.

\section{Conclusion}

The aim of this study was to investigate the bacterial biodiversity of 16 French organic sourdoughs. The lactic acid bacteria diversity of these sourdough was investigated quantitatively and qualitatively combining (i) L. sanfranciscensis-specific qPCR, (ii) global sequencing with MiSeq Illumina technology and (iii) molecular isolate identification. Although L. sanfranciscensis was still the dominant species in 10 of the 16 sourdoughs studied, LAB species diversity was higher than previously described for French organic sourdough, with 16 different species identified considering all the methods used. Regarding both cultural and non-cultural methods, 6 samples showed a non $L$. sanfranciscensis dominance, whatever the characteristics of baker' practices. This study confirmed that $L$. curvatus could be a predominant species in sourdough. Furthermore, L. xianfangensis, $L$. heilongjiangensis and L. koreensis were highlighted for the first time in sourdough, having previously only been found in traditional Asian food. Genomics experiments focusing on the genomic diversity of these species will be performed. Finally, bakers' practices and status, as considered here, did not appeared to be significantly related to LAB diversity and sourdough features.

\section{Acknowledgements}

The authors acknowledge financial support from ANR Bakery-13-ALID-0005 (French National Research Agency), INRA and Oniris. We wish to thank the sixteen bakers as well as Alain and Françoise Bourgeois (Apiliger Earl) for their collaboration on the project, sharing with us their breadmaking knowledge and pleasure in good bread. Thanks are also addressed to Marie-Noëlle Madec and Florence Valence-Bertel from INRA Rennes UMR 1253 Sciences et Technologie du Lait et de l'Euf, Isabelle Hue and Héloïse Debroise from Oniris for their assistance in LAB microbiology, Marc Perez and Thibault Nidelet from INRA Montpellier Science pour l'œnologie for HPLC settings and statistical analyses respectively. 


\section{References}

Addinsoft, T.M., 2007. XISTAT Your data analysis solution. Versión.

Ammor, S., Dufour, E., Zagorec, M., Chaillou, S., Chevallier, I., 2005. Characterization and selection of Lactobacillus sakei strains isolated from traditional dry sausage for their potential use as starter cultures. Food Microbiol. 22, 529-538.

Banu, I., Vasilean, I., Aprodu, I., 2011. Effect of select parameters of the sourdough rye fermentation on the activity of some mixed starter cultures. Food Biotechnol. 25, 275-291.

Barret, M., Briand, M., Bonneau, S., Préveaux, A., Valière, S., Bouchez, O., Hunault, G., Simoneau, P., Jacques, M.-A., 2015. Emergence Shapes the Structure of the Seed Microbiota. Appl. Environ. Microbiol. 81, 1257-1266.

Bessmeltseva, M., Viiard, E., Simm, J., Paalme, T., Sarand, I., 2014. Evolution of bacterial consortia in spontaneously started rye sourdoughs during two months of daily propagation. PloS One 9, e95449.

Bui, T.P.N., Kim, Y.-J., In, J.-G., Yang, D.-C., 2011. Lactobacillus koreensis sp. nov., isolated from the traditional Korean food kimchi. Int. J. Syst. Evol. Microbiol. 61, 772-776.

Caporaso, J.G., Lauber, C.L., Walters, W.A., Berg-Lyons, D., Lozupone, C.A., Turnbaugh, P.J., Fierer, N., Knight, R., 2011. Global patterns of 16S rRNA diversity at a depth of millions of sequences per sample. Proc. Natl. Acad. Sci. 108, 4516-4522.

Cole, J.R., Wang, Q., Chai, B., Tiedje, J.M., 2011. The Ribosomal Database Project: Sequences and Software for High-Throughput rRNA Analysis. Handb. Mol. Microb. Ecol. Metagenomics Complement. Approaches 313-324.

De Vuyst, L., Neysens, P., 2005. The sourdough microflora: biodiversity and metabolic interactions. Trends Food Sci. Technol. 16, 43-56.

De Vuyst, L., Van Kerrebroeck, S., Harth, H., Huys, G., Daniel, H.-M., Weckx, S., 2014. Microbial ecology of sourdough fermentations: diverse or uniform? Food Microbiol. 37, 11-29.

De Vuyst, L., Vancanneyt, M., 2007. Biodiversity and identification of sourdough lactic acid bacteria. Food Microbiol. 24, 120-127.

Devulder, G., Perrière, G., Baty, F., Flandrois, J.P., 2003. BIBI, a bioinformatics bacterial identification tool. J. Clin. Microbiol. 41, 1785-1787.

Edgar, R.C., Haas, B.J., Clemente, J.C., Quince, C., Knight, R., 2011. UCHIME improves sensitivity and speed of chimera detection. Bioinformatics 27, 2194-2200.

Ercolini, D., 2013. High-Throughput Sequencing and Metagenomics: Moving Forward in the CultureIndependent Analysis of Food Microbial Ecology. Appl. Environ. Microbiol. 79, 3148-3155. doi:10.1128/AEM.00256-13 
Ercolini, D., Pontonio, E., De Filippis, F., Minervini, F., La Storia, A., Gobbetti, M., Di Cagno, R., 2013. Microbial ecology dynamics during rye and wheat sourdough preparation. Appl. Environ. Microbiol. 79, 7827-7836.

Foschino, R., Arrigoni, C., Mora, D., Galli, A., others, 2001. Phenotypic and genotypic aspects of Lactobacillus sanfranciscensis strains isolated from sourdoughs in Italy. Food Microbiol. 18, 277-285.

Gobbetti, M., Corsetti, A., 1997. Lactobacillus sanfranciscoa key sourdough lactic acid bacterium: a review. Food Microbiol. 14, 175-188.

Gobbetti, M., Gänzle, M., 2012. Handbook on sourdough biotechnology. Springer Science \& Business Media.

Gobetti, M., Corsetti, A., Rossi, J., 1994. The sourdough microflora. Interactions between lactic acid bacteria and yeasts: metabolism of amino acids. World J Microbiol Biotechnol 10, 275-279.

Gu, C.T., Li, C.Y., Yang, L.J., Huo, G.C., 2013. Lactobacillus heilongjiangensis sp. nov., isolated from Chinese pickle. Int. J. Syst. Evol. Microbiol. 63, 4094-4099.

Gu, C.T., Wang, F., Li, C.Y., Liu, F., Huo, G.C., 2012. Lactobacillus xiangfangensis sp. nov., isolated from Chinese pickle. Int. J. Syst. Evol. Microbiol. 62, 860-863.

Hierro, N., Esteve-Zarzoso, B., González, Á., Mas, A., Guillamón, J.M., 2006. Real-time quantitative PCR (QPCR) and reverse transcription-QPCR for detection and enumeration of total yeasts in wine. Appl. Environ. Microbiol. 72, 7148-7155.

Huys, G., Daniel, H.-M., Vuyst, L.D., 2013. Taxonomy and Biodiversity of Sourdough Yeasts and Lactic Acid Bacteria, in: Gobbetti, M., Gänzle, M. (Eds.), Handbook on Sourdough Biotechnology. Springer US, pp. 105-154.

Jaffrès, E., Sohier, D., Leroi, F., Pilet, M.F., Prévost, H., Joffraud, J.J., Dousset, X., 2009. Study of the bacterial ecosystem in tropical cooked and peeled shrimps using a polyphasic approach. Int. J. Food Microbiol. 131, 20-29.

Katina, K., Arendt, E., Liukkonen, K.-H., Autio, K., Flander, L., Poutanen, K., 2005. Potential of sourdough for healthier cereal products. Trends Food Sci. Technol. 16, 104-112.

Klein, D., 2002. Quantification using real-time PCR technology: applications and limitations. Trends Mol. Med. 8, 257-260.

Kozich, J.J., Westcott, S.L., Baxter, N.T., Highlander, S.K., Schloss, P.D., 2013. Development of a dual-index sequencing strategy and curation pipeline for analyzing amplicon sequence data on the MiSeq Illumina sequencing platform. Appl. Environ. Microbiol. 79, 5112-5120.

Lattanzi, A., Minervini, F., Di Cagno, R., Diviccaro, A., Antonielli, L., Cardinali, G., Cappelle, S., De Angelis, M., Gobbetti, M., 2013. The lactic acid bacteria and yeast microbiota of eighteen sourdoughs used for the manufacture of traditional Italian sweet leavened baked goods. Int. J. Food Microbiol. 163, 71-79. 
Lee, H., Baek, H., Lim, S.B., Hur, J.S., Shim, S., Shin, S.-Y., Han, N.S., Seo, J.-H., 2015. Development of species-specific PCR primers and polyphasic characterization of Lactobacillus sanfranciscensis isolated from Korean sourdough. Int. J. Food Microbiol. 200, 80-86.

Lhomme, E., Lattanzi, A., Dousset, X., Minervini, F., De Angelis, M., Lacaze, G., Onno, B., Gobbetti, M., 2015a. Lactic acid bacterium and yeast microbiotas of sixteen French traditional sourdoughs. Int. J. Food Microbiol. 215, 161-170.

Lhomme, E., Orain, S., Courcoux, P., Onno, B., Dousset, X., 2015b. The predominance of Lactobacillus sanfranciscensis in French organic sourdoughs and its impact on related bread characteristics. Int. J. Food Microbiol. 213, 40-48.

Lhomme, E., Urien, C., Legrand, J., Dousset, X., Onno, B., Sicard, D., 2016. Sourdough microbial community dynamics: An analysis during French organic bread-making processes. Food Microbiol., 19th Meeting of the Club des Bactéries Lactiques 53, Part A, 41-50. doi:10.1016/j.fm.2014.11.014

Lin, X.B., Gänzle, M.G., 2014. Quantitative high-resolution melting PCR analysis for monitoring of fermentation microbiota in sourdough. Int. J. Food Microbiol. 186, 42-48.

Macé, S., Mamlouk, K., Chipchakova, S., Prévost, H., Joffraud, J.-J., Dalgaard, P., Pilet, M.-F., Dousset, X., 2013. Development of a rapid real-time PCR method as a tool to quantify viable Photobacterium phosphoreum bacteria in salmon (Salmo salar) steaks. Appl. Environ. Microbiol. 79, 2612-2619.

Meignen, B., Onno, B., Gélinas, P., Infantes, M., Guilois, S., Cahagnier, B., 2001. Optimization of sourdough fermentation with Lactobacillus brevis and baker's yeast. Food Microbiol. 18, $239-245$.

Meroth, C.B., Walter, J., Hertel, C., Brandt, M.J., Hammes, W.P., 2003. Monitoring the bacterial population dynamics in sourdough fermentation processes by using PCR-denaturing gradient gel electrophoresis. Appl. Environ. Microbiol. 69, 475-482.

Minervini, F., De Angelis, M., Di Cagno, R., Gobbetti, M., 2014. Ecological parameters influencing microbial diversity and stability of traditional sourdough. Int. J. Food Microbiol. 171, 136146.

Minervini, F., Lattanzi, A., De Angelis, M., Celano, G., Gobbetti, M., 2015. House microbiotas as sources of lactic acid bacteria and yeasts in traditional Italian sourdoughs. Food Microbiol. 52, 66-76. doi:10.1016/j.fm.2015.06.009

Naser, S.M., Dawyndt, P., Hoste, B., Gevers, D., Vandemeulebroecke, K., Cleenwerck, I., Vancanneyt, M., Swings, J., 2007. Identification of lactobacilli by pheS and rpoA gene sequence analyses. Int. J. Syst. Evol. Microbiol. 57, 2777-2789.

Rizzello, C.G., Cavoski, I., Turk, J., Ercolini, D., Nionelli, L., Pontonio, E., De Angelis, M., De Filippis, F., Gobbetti, M., Di Cagno, R., 2015. Organic cultivation of Triticum turgidum 
subsp. durum is reflected in the flour-sourdough fermentation-bread axis. Appl. Environ.

Microbiol. 81, 3192-3204.

Robert, H., Gabriel, V., Fontagné-Faucher, C., 2009. Biodiversity of lactic acid bacteria in French wheat sourdough as determined by molecular characterization using species-specific PCR. Int. J. Food Microbiol. 135, 53-59.

Scheirlinck, I., Van der Meulen, R., De Vuyst, L., Vandamme, P., Huys, G., 2009. Molecular source tracking of predominant lactic acid bacteria in traditional Belgian sourdoughs and their production environments. J. Appl. Microbiol. 106, 1081-1092.

Schloss, P.D., Westcott, S.L., Ryabin, T., Hall, J.R., Hartmann, M., Hollister, E.B., Lesniewski, R.A., Oakley, B.B., Parks, D.H., Robinson, C.J., others, 2009. Introducing mothur: open-source, platform-independent, community-supported software for describing and comparing microbial communities. Appl. Environ. Microbiol. 75, 7537-7541.

Stackebrandt, E., Ebers, J., 2006. Taxonomic parameters revisited: tarnished gold standards. Microbiol. Today 33, 152.

Stolz, P., Vogel, R.F., Hammes, W.P., 1995. Utilization of electron acceptors by lactobacilli isolated from sourdough. Z. Für Lebensm.-Unters. Forsch. 201, 402-410.

Sun, Z., Harris, H.M., McCann, A., Guo, C., Argimón, S., Zhang, W., Yang, X., Jeffery, I.B., Cooney, J.C., Kagawa, T.F., others, 2015. Expanding the biotechnology potential of lactobacilli through comparative genomics of 213 strains and associated genera. Nat. Commun. 6 .

Team, Rs., 2015. RStudio: integrated development for R. RStudio, Inc., Boston, MA.

The NCBI Handbook, 2nd ed, 2013. . National Center for Biotechnology Information (US).

Thiele, C., Gänzle, M.G., Vogel, R.F., 2002. Contribution of sourdough lactobacilli, yeast, and cereal enzymes to the generation of amino acids in dough relevant for bread flavor. Cereal Chem. 79, $45-51$.

Torriani, S., Felis, G.E., Dellaglio, F., 2001. Differentiation of Lactobacillus plantarum, L. pentosus, and $L$. paraplantarum by recA gene sequence analysis and multiplex PCR assay with recA gene-derived primers. Appl. Environ. Microbiol. 67, 3450-3454.

Valcheva, R., Ferchichi, M.F., Korakli, M., Ivanova, I., Gänzle, M.G., Vogel, R.F., Prévost, H., Onno, B., Dousset, X., 2006. Lactobacillus nantensis sp. nov., isolated from French wheat sourdough. Int. J. Syst. Evol. Microbiol. 56, 587-591.

Valcheva, R., Korakli, M., Onno, B., Prévost, H., Ivanova, I., Ehrmann, M.A., Dousset, X., Gänzle, M.G., Vogel, R.F., 2005. Lactobacillus hammesii sp. nov., isolated from French sourdough. Int. J. Syst. Evol. Microbiol. 55, 763-767.

Valmorri, S., Tofalo, R., Settanni, L., Corsetti, A., Suzzi, G., 2010. Yeast microbiota associated with spontaneous sourdough fermentations in the production of traditional wheat sourdough breads of the Abruzzo region (Italy). Antonie Van Leeuwenhoek 97, 119-129. 
Venturi, M., Guerrini, S., Granchi, L., Vincenzini, M., 2012. Typing of Lactobacillus sanfranciscensis isolates from traditional sourdoughs by combining conventional and multiplex RAPD-PCR profiles. Int. J. Food Microbiol. 156, 122-126.

Vera, A., Rigobello, V., Demarigny, Y., 2009. Comparative study of culture media used for sourdough lactobacilli. Food Microbiol. 26, 728-733.

Wang, Q., Garrity, G.M., Tiedje, J.M., Cole, J.R., 2007. Naive Bayesian classifier for rapid assignment of rRNA sequences into the new bacterial taxonomy. Appl. Environ. Microbiol. 73, 5261-5267.

Weisburg, W.G., Barns, S.M., Pelletier, D.A., Lane, D.J., 1991. 16S ribosomal DNA amplification for phylogenetic study. J. Bacteriol. 173, 697-703.

Zeppa, G., Conterno, L., Gerbi, V., 2001. Determination of organic acids, sugars, diacetyl, and acetoin in cheese by high-performance liquid chromatography. J. Agric. Food Chem. 49, 2722-2726.

Zheng, B., Jiang, X., Cheng, H., Xu, Z., Li, A., Hu, X., Xiao, Y., 2015. Complete genome sequence of Lactobacillus heilongjiangensis DSM 28069T: Insight into its probiotic potential. J.

Biotechnol. 216, 65-66. doi:10.1016/j.jbiotec.2015.09.023 

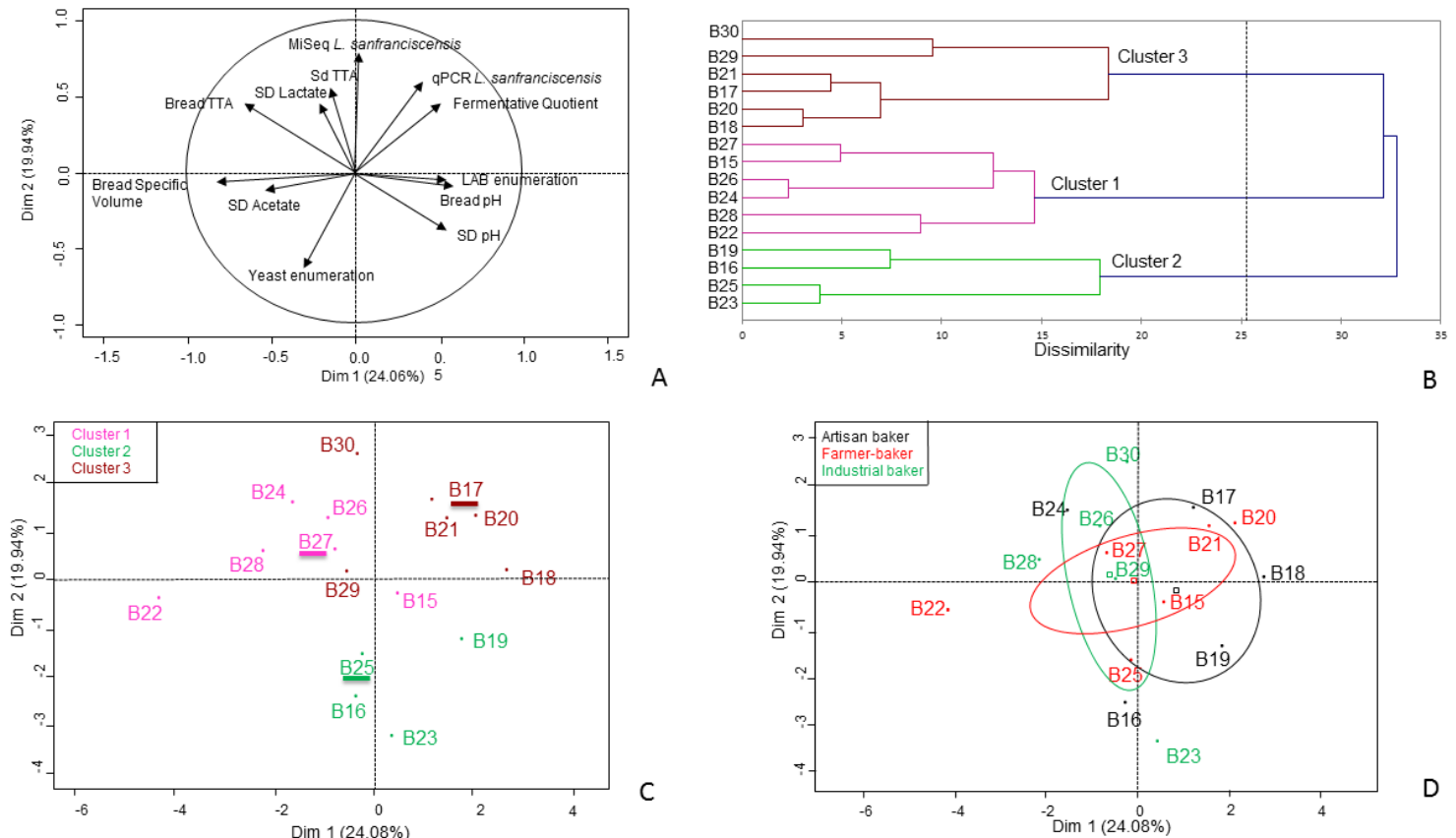

Figure 1 
Figure captions

Figure 1: Principal Component Analysis and Hierarchical Ascendant Classification applied to sourdoughs (SD) B15 to B30 and breads characteristics (physicochemical results, yeast and LAB counts and Lactobacillus sanfranciscensis qPCR estimation and MiSeq relative abundance)

1A - Variables factor map of first and second principal components after Principal Component Analysis (PCA)

1B - Hierarchical Ascendant Classification (HAC) of sixteen French organic sourdoughs based on physicochemical and microbiological criteria

1C - Score and loading plots of first and second principal components after Principal Component Analysis (PCA).Underlined data represented centroids samples of HAC clusters: Cluster $1 \mathrm{O}$, Cluster $2 \mathrm{O}$ and Cluster $3 \mathrm{O}$

1D - Confidence ellipses based on bakers' groups 


\begin{tabular}{l|ll}
\hline Sourdough & $\begin{array}{l}\text { Location of the bakery in } \\
\text { France }\end{array}$ & Bakers' class \\
\hline B15 & Hérault (South) & Farmer baker \\
B16 & Yvelines (Paris area) & Artisan baker \\
B17 & Somme (North) & Artisan baker \\
B18 & Paris & Artisan baker \\
B19 & Aveyron (South) & Artisan baker \\
B20 & Alpes-Maritimes & Farmer baker \\
B21 & Morbihan (West) & Farmer baker \\
B22 & Lot-et-Garonne (South) & Farmer baker \\
B23 & Bas-Rhin (East) & Industrial baker \\
B24 & Vaucluse (South) & Artisan baker \\
B25 & Haut-Rhin (East) & Farmer baker \\
B26 & Côtes-d'Armor (West) & Industrial baker \\
B27 & Puy-de-Dôme (Center) & Farmer baker \\
B28 & Paris & Industrial baker \\
B29 & Aude (South) & Industrial baker \\
B30 & Savoie (East) & Industrial baker \\
\hline
\end{tabular}

Table 1: Location and classification of the 16 French bakers selected 


\begin{tabular}{|c|c|c|c|}
\hline $\begin{array}{l}\text { Primer } \\
\text { set }\end{array}$ & Oligonucléotide sequence & Target gene & Reference \\
\hline fD1 & 5'-AGAGTTTGATCCTGGCTCAG-3' & $16 \mathrm{~S}$ rRNA & Weisburg \\
\hline rD1 & 5'-TAAGGAGGTGATCCAGCC-3' & & \\
\hline Sp1 & 5'-ACTCCTACGGGAGGCAGCA-3' & $\begin{array}{l}\text { rDNA } 16 \mathrm{~S} \\
\text { position } 338 \\
\text { forward }\end{array}$ & $\begin{array}{l}\text { Lhomme } \\
\text { et al., } \\
2015 \mathrm{a}\end{array}$ \\
\hline $\mathrm{Sp} 2$ & 5'-ACCGCGGCTGCTGGCACG-3' & $\begin{array}{l}\text { rDNA } 16 \mathrm{~S} \\
\text { position } 514 \\
\text { reverse }\end{array}$ & \\
\hline Sp3 & 5'-GATACCCTGGTAGTCCACG & $\begin{array}{l}\text { rDNA } 16 \mathrm{~S} \\
\text { position } 810 \\
\text { forward }\end{array}$ & \\
\hline Sp4 & 5'-CTCGTTGCGGGACTTAAC-3' & $\begin{array}{l}\text { rDNA } 16 S \\
\text { position } \\
1100\end{array}$ & \\
\hline SP5 & 5'-GGTACCTTGTTACGACTT-3' & $\begin{array}{l}\text { rDNA } 16 S \\
\text { position } \\
1089 \\
\text { reverse }\end{array}$ & \\
\hline 702-F & 5'-AATTGCCTTCTTCCGTGTA-3' & katA & $\begin{array}{l}\text { Ammor et } \\
\text { al., } 2005\end{array}$ \\
\hline $310-\mathrm{R}$ & 5'-AGTTGCGCACAATTATTTTC-3' & & \\
\hline paraF & 5'-GTCACAGGCATTACGAAA AC-3' & recA & $\begin{array}{l}\text { Torriani et } \\
\text { al., } 2001\end{array}$ \\
\hline planF & 5'-CCGTTTATGCGGAACACC TA-3' & & \\
\hline pentF & 5'-CAGTGGCGCGGTTGATAT C-3' & & \\
\hline pREV & 5'-TCGGGATTACCAAACATCAC-3' & & \\
\hline $21-\mathrm{F}$ & 5'-ATGATYGARTTTGAAAAACC-3' & rpoA & $\begin{array}{l}\text { Naser et } \\
\text { al., } 2007\end{array}$ \\
\hline $23-\mathrm{R}$ & 5'-ACYTTVATCATNTCWGVYTC-3' & & \\
\hline LS-1F & 5'-TGCAAGCACGTTCTCTAGAAA-3' & phes & $\begin{array}{l}\text { Scheirlinck } \\
\text { et al., } 2009\end{array}$ \\
\hline
\end{tabular}


LS-1R 5'-GAGTTGGATCGTCGGTATCA-3'

\begin{tabular}{|c|c|c|c|}
\hline \multirow[t]{3}{*}{$515 f$} & 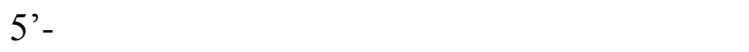 & MiSeq PCR & Caporaso \\
\hline & CTTTCCCTACACGACGCTCTTCCGATCT- & $16 \mathrm{~S}(\mathrm{~V} 4)$ & et al., 2011 \\
\hline & $3^{\prime}$ & & \\
\hline \multirow[t]{3}{*}{$806 r$} & 5 - & & \\
\hline & GGAGTTCAGACGTGTGCTCTTCCGATCT- & & \\
\hline & 3 ' & & \\
\hline
\end{tabular}

Table 2: Oligonucleotides primers used for PCR amplification and sequencing 


\begin{tabular}{|c|c|c|c|c|c|c|c|c|c|c|c|c|c|c|c|c|c|c|c|}
\hline \multirow{2}{*}{$\begin{array}{l}\begin{array}{l}\text { Sourdough } \\
\text { samples }\end{array} \\
\text { B15 }\end{array}$} & \multicolumn{3}{|c|}{$\begin{array}{c}\text { LAB } \\
\text { enumeration } \\
(\log \mathrm{CFU} / \mathrm{g})\end{array}$} & \multicolumn{3}{|c|}{$\begin{array}{c}\text { Yeast } \\
\text { enumeration } \\
(\log \mathrm{CFU} / \mathrm{g})\end{array}$} & \multirow{2}{*}{$\begin{array}{l}\text { Ratio } \\
\text { Yeast/ } \\
\text { LAB } \\
(\%) \\
1.66\end{array}$} & \multicolumn{2}{|c|}{ Sourdough $\mathrm{pH}$} & \multicolumn{3}{|c|}{$\begin{array}{l}\text { Sourdough } \\
\text { TTA }\end{array}$} & \multicolumn{3}{|c|}{$\begin{array}{c}\text { Sourdough } \\
\text { Acetate }(\mathrm{g} / \mathrm{kg})\end{array}$} & \multicolumn{3}{|c|}{$\begin{array}{c}\text { Sourdough } \\
\text { Lactate }(\mathrm{g} / \mathrm{kg})\end{array}$} & \multirow{2}{*}{$\begin{array}{c}\begin{array}{c}\text { Sourdough } \\
\text { Fermentative } \\
\text { Quotient }\end{array} \\
1.28\end{array}$} \\
\hline & 9.42 & + & 0.03 & 7.64 & \pm & 0.08 & & 3.82 & \pm 0.01 & 18.3 & \pm & 6.12 & 1.57 & \pm & 0.08 & 3.37 & \pm & 0.02 & \\
\hline B16 & 9.11 & \pm & 0.04 & 7.67 & \pm & 0.12 & 3.63 & 4.02 & \pm 0.01 & 13.4 & \pm & 2.45 & \multicolumn{3}{|c|}{ ND } & \multicolumn{3}{|c|}{ ND } & ND \\
\hline B17 & 9.16 & \pm & 0.10 & 6.70 & \pm & 0.08 & 0.35 & 3.84 & \pm 0.01 & 15.0 & \pm & 0.07 & 0.91 & \pm & 0.02 & 8.71 & \pm & 0.38 & 5.66 \\
\hline B18 & 9.44 & \pm & 0.11 & 6.99 & \pm & 0.08 & 0.36 & 3.98 & \pm 0.01 & 14.4 & \pm & 0.32 & 1.41 & \pm & 0.09 & 8.74 & \pm & 0.16 & 3.70 \\
\hline B19 & 9.62 & \pm & 0.19 & 7.01 & \pm & 0.04 & 0.25 & 4.03 & \pm 0.01 & 13.3 & & 0.31 & 1.53 & \pm & 0.07 & 5.29 & \pm & 0.07 & 2.06 \\
\hline B20 & 9.60 & \pm & 0.10 & 6.78 & \pm & 0.01 & 0.15 & 3.87 & \pm 0.01 & 19.8 & & 0.32 & \multicolumn{3}{|c|}{ ND } & \multicolumn{3}{|c|}{ ND } & ND \\
\hline B21 & 8.97 & \pm & 0.14 & 7.20 & \pm & 0.07 & 1.69 & 3.70 & \pm 0.01 & 18.1 & \pm & 0.71 & 1.22 & \pm & 0.01 & 9.17 & \pm & 0.12 & 4.47 \\
\hline B22 & 8.09 & \pm & 0.03 & 7.68 & \pm & 0.10 & 38.9 & 3.70 & 0.01 & 14.9 & \pm & 0.3 & 4.44 & \pm & 0.05 & 7.62 & \pm & 0.04 & 1.06 \\
\hline B23 & 9.02 & \pm & 0.03 & 7.69 & \pm & 0.12 & 4.68 & 3.86 & \pm 0.00 & 14.5 & \pm & 0.16 & 2.62 & \pm & 0.04 & 7.82 & \pm & 0.07 & 1.99 \\
\hline B24 & 8.81 & \pm & 0.04 & 7.58 & \pm & 0.14 & 5.89 & 3.85 & $\pm \quad 0.01$ & 21.3 & \pm & 1.26 & 2.48 & \pm & 0.01 & 11.96 & \pm & 0.07 & 2.87 \\
\hline B25 & 8.62 & \pm & 0.05 & 7.43 & \pm & 0.16 & 6.46 & 3.80 & \pm 0.01 & 14.1 & \pm & 0.16 & 1.63 & \pm & 0.03 & 7.10 & \pm & 0.11 & 2.59 \\
\hline B26 & 9.29 & \pm & 0.04 & 7.45 & \pm & 0.13 & 1.45 & 3.77 & \pm 0.01 & 18.0 & \pm & 0.00 & 2.19 & \pm & 0.09 & 10.89 & \pm & 0.13 & 2.97 \\
\hline B27 & 9.46 & \pm & 0.01 & 7.52 & \pm & 0.07 & 1.15 & 3.62 & \pm 0.00 & 16.5 & \pm & 0.15 & 1.75 & \pm & 0.03 & 7.86 & \pm & 0.28 & 2.66 \\
\hline B28 & 8.54 & \pm & 0.09 & 6.74 & \pm & 0.02 & 1.58 & 0.0 & 0.00 & 19.2 & \pm & 0.16 & 3.34 & \pm & 0.33 & 8.31 & \pm & 0.79 & 1.48 \\
\hline B29 & 7.19 & \pm & 0.09 & 7.01 & \pm & 0.02 & 66.07 & 3.83 & 0.00 & 14.8 & \pm & 0.15 & 1.62 & \pm & 0.07 & 8.09 & \pm & 0.01 & 2.97 \\
\hline B30 & 8.38 & \pm & 0.35 & 5.92 & \pm & 0.06 & 0.35 & 3.81 & 0.06 & 14.8 & \pm & 1.18 & 1.09 & \pm & 0.02 & 8.50 & \pm & 0.16 & 4.65 \\
\hline
\end{tabular}

Table 3: Total LAB and yeast enumeration ( $\log \mathrm{CFU} / \mathrm{g}$ ); physicochemical characteristics of sourdoughs and related breads (mean values \pm standard deviation). ND : Not determined 


\begin{tabular}{|c|c|c|c|c|}
\hline $\begin{array}{l}\text { Sourdough } \\
\text { samples }\end{array}$ & $\begin{array}{c}\text { Quantification } \\
\text { of } \\
L . \\
\text { sanfranciscensis } \\
\text { (log CFU/g) by } \\
\text { qPCR }\end{array}$ & $\begin{array}{l}\text { Ratio } \\
\text { qPCR } \\
\text { results/ } \\
\text { LAB } \\
\text { count }\end{array}$ & Species relative abundance (\%) by NGS Miseq & $\begin{array}{l}\text { Species identified in } \\
\text { sourdough } \\
\text { by biomolecular method }(\%)\end{array}$ \\
\hline B15 & 10.29 & 1.09 & L. sanfranciscensis (99.8\%), Lactobacillus sp. (0.1\%) & $\begin{array}{l}\text { L. sanfranciscensis }(86 \%), L \text {. } \\
\text { plantarum }(14 \%)\end{array}$ \\
\hline B16 & 8.41 & 0.92 & $\begin{array}{l}\text { L. sanfranciscensis }(0.1 \%), \text { Lactobacillus sp. }(12.0 \%) \text {, } \\
\text { L.curvatus }(75.2 \%), \text { L. sakei }(0.7 \%) \text {, Weissella } \\
(0.2 \%)\end{array}$ & $\begin{array}{l}\text { L. curvatus }(90 \%), L \text {. } \\
\text { plantarum }(10 \%)\end{array}$ \\
\hline B17 & 9.27 & 1.01 & L. sanfranciscensis $(99.8 \%)$ & L.sanfranciscensis $(100 \%)$ \\
\hline B18 & 9.47 & 1.01 & L. sanfranciscensis $(99.9 \%)$ & L.sanfranciscensis (100\%) \\
\hline B19 & 9.58 & 0.99 & L. sanfranciscensis $(99.9 \%)$ & L.sanfranciscensis $(100 \%)$ \\
\hline B20 & 10.06 & 1.05 & L. sanfranciscensis $(99.7 \%)$ & L.sanfranciscensis (100\%) \\
\hline B21 & 9.48 & 1.05 & $\begin{array}{l}\text { L. sanfranciscensis }(99.8 \%) \text {, Lactobacillus sp. }(0.1 \%) \text {, } \\
\text { L. koreensis or L. brevis }(0.1 \%)\end{array}$ & $\begin{array}{l}\text { L.sanfranciscensis (54\%), L. } \\
\text { plantarum }(8 \%), \quad L . \\
\text { xiangfangensis }(15 \%), L . \\
\text { brevis }(23 \%)\end{array}$ \\
\hline B22 & 7.85 & 0.97 & L. sanfranciscensis $(99.9 \%)$ & L.sanfranciscensis $(100 \%)$ \\
\hline B23 & 4.41 & 0.43 & $\begin{array}{l}\text { L. koreensis or L. brevis }(80.0 \%), \text { L. heilongjiangensis } \\
\text { or L. farminis or L. crustorum }(16.7 \%), \text { L. nantensis } \\
(0.8 \%), \text { Leuconostoc (order) }(0.4 \%), \text { L. } \\
\text { sanfranciscensis }(0.2 \%) \text {, }\end{array}$ & $\begin{array}{l}\text { L. heilongjiangensis }(37.5 \%) \text {, } \\
\text { L. koreensis }(25 \%), \quad \text { L. } \\
\text { plantarum }(25 \%), \text { L. curvatus } \\
(12.5 \%) \text {, }\end{array}$ \\
\hline B24 & 8.03 & & L. sanfranciscensis $(99.9 \%)$ & L sanfranciscensis $(100 \%)$ \\
\hline B25 & 7.40 & 0.85 & $\begin{array}{l}\text { Lactobacillus sp. }(61.9 \%), \text { L. sanfranciscensis } \\
(36.1 \%), \text { L. brevis }(0.9 \%)\end{array}$ & $\begin{array}{l}\text { L. brevis }(69 \%), \text { L. plantarum } \\
(15 \%), \quad L . \\
\text { sanfranciscensis }(8 \%), L . \\
\text { paralimentarius }(8 \%)\end{array}$ \\
\hline B26 & 8.99 & 0.97 & $\begin{array}{l}\text { L. sanfranciscensis }(98.6 \%), \text { Lactobacillus sp. }(0.6 \%) \text {, } \\
\text { L. parabrevis }(0.6 \%)\end{array}$ & $\begin{array}{l}\text { L. sanfranciscensis ( } 75 \%), L \text {. } \\
\text { plantarum }(25 \%)\end{array}$ \\
\hline B27 & 9.09 & 0.96 & L. sanfranciscensis $(99.8 \%)$ & L.sanfranciscensis $(100 \%)$ \\
\hline B28 & 7.19 & 0.84 & $\begin{array}{l}\text { L. sanfranciscensis }(88.8 \%), \text { L. pontis }(4.3 \%), L \text {. } \\
\text { parabrevis }(2.4 \%), \text { L. buchneri }(0.8 \%), \text { L. diolivorans } \\
(2.3 \%)\end{array}$ & $\begin{array}{l}\text { L. sanfranciscensis }(40 \%), L \text {. } \\
\text { pontis }(33 \%), \quad L . \\
\text { diolivorans }(13 \%), L . \\
\text { paracasei }(7 \%), \\
\text { L. parabuchneri }(7 \%)\end{array}$ \\
\hline B29 & 8.23 & 1.15 & $\begin{array}{l}\text { L. sanfranciscensis }(99.6 \%), \text { L. koreensis or L. brevis } \\
(0.2 \%)\end{array}$ & $\begin{array}{l}\text { L. plantarum }(9 \%), L . \\
\text { xiangfangensis }(55 \%), \\
\text { Leuconostoc citreum }(36 \%)\end{array}$ \\
\hline B30 & 9.46 & 1.13 & $\begin{array}{l}\text { L. sanfranciscensis }(99.2 \%), \text { Weissella }(0.4 \%) \text {, } \\
\text { Pediococcus pentosaceus }(0.2 \%), \text { Lactobacillus sp. } \\
(0.1 \%), \text { L. koreensis or L. brevis }(0.1 \%)\end{array}$ & $\begin{array}{l}\text { P. pentosaceus }(55 \%) \text {, } \\
\text { Weisella confusa }(27 \%) \text {, } \\
\text { L. sanfranciscensis }(18 \%)\end{array}$ \\
\hline
\end{tabular}


Table 4: Microbial diversity of 16 French organic sourdoughs. Estimation of L. sanfranciscensis by qPCR (log CFU/g), relative abundance (expressed as \%) of bacterial taxonomic units by the MiSeq method and isolate identification by $16 \mathrm{~S}$ rDNA sequencing (number of isolates per species / total number of isolates per sourdough expressed as \%) 


\begin{tabular}{ccccccccc}
\hline Class & $\begin{array}{c}\text { N LAB } \\
(\log \text { CFU/g) }\end{array}$ & $\begin{array}{c}\text { N Yeast } \\
(\log \text { CFU/g) }\end{array}$ & $\begin{array}{c}\text { L. sanfranciscensis } \\
(\log \text { CFU/g) }\end{array}$ & $\begin{array}{c}\text { Relative Abundance } \\
\text { L. sanfranciscensis } \\
(\%)\end{array}$ & $\begin{array}{c}\text { Sourdough } \\
\mathrm{pH}\end{array}$ & $\begin{array}{c}\text { Sourdough } \\
\mathrm{TTA}\end{array}$ & $\begin{array}{c}\text { Sourdough } \\
\text { Acetic acid } \\
(\mathrm{g} / \mathrm{kg})\end{array}$ & $\begin{array}{c}\text { Sourdo } \\
\text { Lactic a } \\
(\mathrm{g} / \mathrm{kg}\end{array}$ \\
\hline 1 & 8.34 & 7.44 & 8.57 & 7.45 & 97.8 & 3.73 & 18.03 & 2.63 \\
2 & 9.09 & 7.45 & 9.33 & 34.08 & 3.93 & 13.83 & 1.83 & 6.34 \\
3 & 8.79 & 6.77 & & 99.67 & 3.84 & 16.15 & 1.28 & 8.66 \\
\hline
\end{tabular}

Table 5: Cluster class centroids obtained by Hierarchical Ascendant Classification based on bread and sourdough physico-chemical and microbiological criteria 